\title{
Gastrointestinal Absorption Induction
}

National Cancer Institute

\section{Source}

National Cancer Institute. Gastrointestinal Absorption Induction. NCI Thesaurus. Code C41490.

Gastrointestinal Absorption Induction involves initiation of activities of uptake from the intestinal lumen of fluids, solutes, proteins, fats, and other nutrients into the intestinal epithelial cells, blood, lymph, or interstitial fluids. 